\title{
NUMERICAL ANALYSIS AND FINITE ELEMENT SIMULATION OF AXIAL STIFFNESS OF OVERHEAD TRANSMISSION LINE CONDUCTOR
}

\section{HADIYA PRITESH DULABHAI ${ }^{1}$, DR. N. S. PARTHASARATHY ${ }^{2} \&$ DR. GURUMOOTHYS. HEBBAR ${ }^{3}$}

\author{
${ }^{1}$ Assistant Professor, Department of Mechanical \& Automobile Engineering, CHRIST (Deemed to be University), \\ Bengaluru, Karnataka, India \\ ${ }^{2,3}$ Professor, Department of Mechanical \& Automobile Engineering, CHRIST (Deemed to be University),
}

Bengaluru, Karnataka, India

\begin{abstract}
Cables, overhead electrical conductors, and ropes are flexible structural assemblies made out of a central core and number of wires which are twisted together to form a complex helical structure. In the majority, cables are subjected to axial loading primarily, followed by the associated twisting. Depending upon the application, they are additionally loaded in bending also. The mechanical behavior of the cables can be predicted by various mathematical models reported in the literature. The mathematical model can predict the overall global behavior of the cable well. However, the local behavior of the cable must be included to have intricate realistic studies. In this paper, an attempt is made to predict the response of the cable considering all the local effects under axial loading. A core with a single layer of six wires is modelled using the helical rod concept and its mechanical behavior is investigated by means of Finite Element Analysis (FEA). The effect of axial loading on the cable is proposed to be studied as a function of various cable axial strains. The core-wire and the wire-wire contact mode of the cable assembly have been considered with due consideration of the contact forces and the associated frictional effects. The reduction in cable stiffness has been studied under various slip modes. The analytical and FEA results are validated with experimental tests on a single-layered transmission line conductor.

KEYWORDS: Electrical Conductors, Axial Load, Friction\& Finite Element Analysis (FEA)
\end{abstract}

Received: Feb 07, 2020; Accepted: Feb 27, 2020; Published: Mar 13, 2020; Paper Id.: IJMPERDAPR202050

\section{INTRODUCTION}

Cables are made of helically wound wires and have a wide range of engineering applications. These are used as conductors in overhead electrical power transmission lines, cables in electrical substations, support elements in suspension, cable-stayed bridges, guyed towers, as wire rope in material handling equipment and other related lifting devices. Thecables are made of a straight central core assembly and several concentric layers of wires helically wound over the core with alternating lay angles and with the same or different materials. The wire ropes are the assembly of stranded cables consisting of a central strand and a few strands twisted and helically wound over the central core in one and many alternating layers. The loading on such cable assemblies is generally the axial pull or tension and torsion. The cable assemblies are subjected to bending loads, additionally when they are under transverse vibration as in overhead electrical transmission lines or when they are passed around pulleys/sheaves in material handling or hoisting/lifting applications. However, since the base load on all the cable assemblies is the axial tension, most of the analysis schemes concentrate on the axial loading first and super impose the effects of 
other loading later. Based on the geometrical arrangement of the wires and core, three types of contacts can emerge (Figure1). Ifthe wireswith in the strands are touching the core and the neighbouring wires, it is called as combined contact(figure $1 \mathrm{a}$ ), and if the contact is established between the core and the wires alone but not with wire to wire,then it is called as radial contact (figure $1 \mathrm{~b}$ ); If the contact is found to exist between wires in the same layer only and not with the core, then it is called as Lateral/Hoop contact (figure $1 \mathrm{c}$ ).
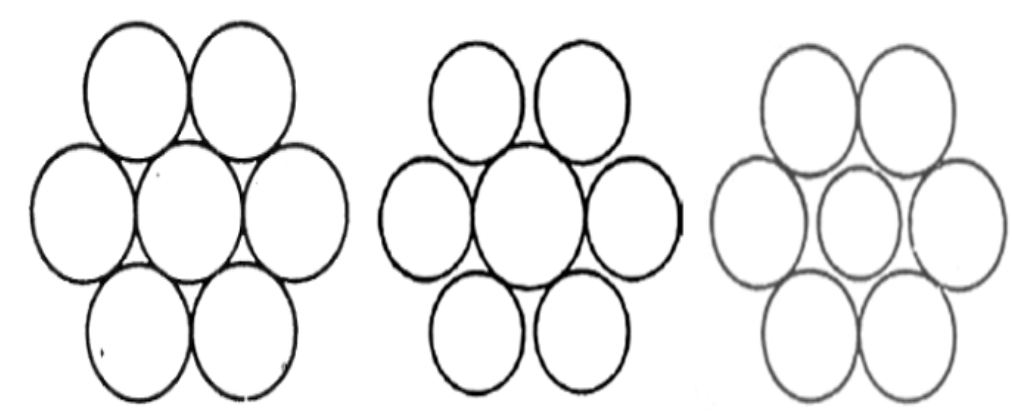

Figure 1: a) Combined Contact b) Radial Contact c) Lateral Contact.

The nature of the contacts between the wire and the core, the extent of the frictional forces generated and the associated slip/movement of the wires at the contact interfaces contribute to the axial stiffness of the cable assembly at that loading condition. Two extreme behaviors of the stranded cable assembly exist -i) the monolithic behavior, wherein all the wires in the cable behave as a single welded unit, ii) the loose wire behavior, wherein all the wires behave individually or independently.The former assumption leads to a higher or maximum cable stiffness, owing to the presence of infinite friction between the wires and the latter loose wire assumption leads to the lowest or minimum cable stiffness, owing to the complete absence of friction among the wires. But in reality, the actual cable behavior is decided by the stiffness value, lying in the broader range depending on the amount of friction present at the wire interfaces. Though various mathematical models have been developed for predicting the stiffness of the strand, most of the models fail to capture the realistic cases of interactionof the wires in the strand. Hence, a detailed literature survey had been undertaken in this direction and the salient research works are presented.

Costello(Costello, 1983) had developed the basic mechanics relations for an axially loaded strand under core wire radial contact mode and obtained a solutions in the elastic range. The cable was treated as an assembly of curved rods and the strand equilibrium equations were obtained from the individual wire forces and moments based on the assumption of infinite friction at the core wire interfaces. This yielded maximum value for the axial stiffness of the cable. Costello's theoretical results were found to tally with the detailed experiments carried out by Utting \& Jones(Utting \& Jones, 1987a, 1987b) on single layered steel strands under axial loading with various end restraints. The research contributions of Costello(Costello, 1990) were compiled in a monograph/book form which became the base line work in cable analysis and had been adopted as a bench mark reference by many researchers in this area.

Since, the cable assembly is quite complex in modelling and analysis, particularly, when it is to deal with the contact and friction phenomenon, the recent researchers have adopted finite element modeling techniques to give a fair representation of the behaviour and flexibility in handling the variations, as an alternative to the numerical solution of the naturallynonlinear equations. Chiang(Chiang, 1996)characterized a single layered cable and studied its axial stiffness at the cable ends and at the middle cross section by considering six parameters- radius of core and helical wire, helix angle, 
strand length, contact conditions at core-helical wire under two sets of boundary conditions i.e.- fixed-fixed and fixed-free. The interaction of the six parameters on the axial stress variations was studied by FEM and design of experiments. The axial stiffness was evaluated for core-wire contact strand with infinite friction or perfect adhesive contact and the finite element analysis results and design of experiments agreedreasonably.

Jiang(W. G. Jiang, Yao, \& Walton, 1999)adopted a finite element model to explain the global behaviour of an axially loaded single layeredstrand in the core-wire radial contact mode to include the local effects of tension, shear, bending, torsion, radial contact and friction. The axial stiffness results showed a good agreement with Costello(Costello, 1990)elastic theoryand also with the experimental results of Utting and Jones(Utting \& Jones, 1987a) in the elastic range where there is no relative movement at the core wire interface. However, the effects of the local forces at the contact interference were not considered.

Elata et al(Elata, Eshkenazy, \& Weiss, 2004)proposed a model to evaluate the mechanical response of a wire rope with an independent wire rope core subjected to axial tension and torsion. The wireswere assumed to yield a fiber response, completely neglecting the bending and torsion stiffness effects. However, the model considered the double helix configuration of the individual wire in the wire rope. Two specific multistrand constructions $-6 \times 36$ IWRC rotating rope of $14 \mathrm{~mm}$ diameter and a $18 \times 7$ IWRC non rotating rope of $14 \mathrm{~mm}$ diameter were modelled simulated and tested. The predicted mechanical response was compared with its experimental measurements in a tension-torsion machine. The rope stiffness matrix coefficients predicted by the proposed model were found to be little higher than the experimental results. Two extreme cases of friction- unlimited friction between adjacent wires and fully lubricated arrangement with no friction among the wires were studied.

Jiang et al(Wen Guang Jiang, Warby, \& Henshall, 2008)extended their earlier study on single layered cable by considering the combined contact of the helical wires, touching among themselves and also touching the central core in the undeformed configuration. As this had become a statically indeterminate problem, FEM was used to solve it. Three dimensional solid and linear isoparametric brick element were used for discretization. All the contact interfaces were treated with no relative sliding and the complete structural analysis was studied with a basic sector that involves $1 / 6$ of the complete cross section. The predicted FEM results of the axial force and torque agreed with that of Costello in the linear range. The response analysis included the local contact deformation at all the wire interfaces resulting in radial deformation and change of helix radius. When a cyclic loading analysis was performed with inclusion of friction a hysteretic behaviour had been observed.

Usabiaga et al(Usabiaga, Ezkurra, Madoz, \& Pagalday, 2008)introduced new theoretical method for modelling wire rope subjected to axial tension and torsion. The method was based on the beam assumptions and accounted the double helix wires, based on curved rod theory. The wire interfaces were treated unlubricated and no relative sliding between adjacent wires was permitted. A basic $18 \mathrm{~mm}-7 \times 7$ WSC strand steel rope was studied with regular and Lang lay construction. The global response of axial stiffness shows good agreement with test results of Costello(Costello, 1990), while torsional stiffness results showed a variation due to the consideration of refined double helix expression as against Costello model.

Stanova et al(Stanova, Fedorko, Fabian, \& Kmet, 2011)have developed mathematical model to generate single, multilayer strands and wire ropes, considering the single helix configuration of wires in the strand and double helix configuration arrangement of the strand to form wire ropes. The parametric equations were developed to account the nature 
of the lay arrangement and the generation of the strand, ropes in Part 1 of the paper. The geometric parametric equations were implemented in CATIA V5 and 3D modelling of single and multilayer strands were created and analysed through ABAQUAS/Explicit Software for axial tension loads. Eight noded linear brick elements with three degree of freedom per node were used for mesh generation. The surface to surface contact was established between wires in the same layer and that with adjacent layers with Coulomb friction law with a friction coefficient of 0.2. Fixed-free end boundary conditions were adopted. The theoretical results of axial stiffness and FEM results were found to lie within an error of $8.5 \%$ when the strands axial strain was varied from 0 to 0.008 .

Ivan Argatov(Argatov, 2011)formulated refined the discrete model for a simple wire rope strand to evaluate its axial response by accounting its transverse contraction through Poisson'seffect and wire flattering due to contact forces on the wires. The nonlinear contact deformation phenomenon was treated as a friction less unilateral plain strain problem using asymptotic equations. All the stiffness matrix elements were obtained for radial and combined contact model and compared with experimental data and FEM simulations. Frictional effects were neglected in this model.

The various cable modelling techniques are reviewed and presented in a comprehensive form by Spak et al(Spak, Agnes, \& Inman, 2013)along with their limitations.

Kastratovic et al(Kastratović, Vidanović, Bakić, \& Rašuo, 2014)carried numerical analysis on a $1 \times 19$ stainless steel strand and a $7 \times 19$ IWS sling rope through finite element analysis. Two types of contacts i.e bounded and friction were investigated for fixed-free end condition. The combined contact mode was assumed to exist and the cable was analysed for its axial stiffness. The FEM results were compared with that of Costello and found to have been in close agreement up to a strain value of 0.008 in the elastic range for the strain values greater than 0.008 the FEM results differ from Costello as plastic behaviour was observed due to the frictional nonlinearcharacteristics.

Foti et al(Foti \& de Luca di Roseto, 2016)adopted a new formulation for modelling the elastic plastic behaviour of the metallic strand subjected to axial tension and torsional loads. Simple unique axial constitutive equations were derived considering the internal structure of the strand and plasticity effects were taken into account. The finite element model developed to consider these variations had given reasonably close agreements with the analytical and experimental results.

Based on the literature survey, it can be observed that the modelling of cable is very complex due to the nature of the behaviour of the helical wire during loading and deformed states. The cable behaviour is highly dependent on the interaction of the wires which is influenced by the nature of the contacts and the magnitude of the contact forces that are set in.

This aspect has not been adequately handled in the modelling by the researchers to predict the cable behavior. The modelling of the cable assembly is to sufficiently explain the contact phenomenon- the contact locations, the contact forces and the contact deformations that occur on the wire, the role of friction force at the wire contact interface and the associated slip/movement of the wires. Though very few researchers have addressed the contact and friction phenomenon, they have not handled all the contact possibilities or have partially attempted them, since the conventional mathematical procedures are quite involved with the high level of complexity.

Hence, this paper aims to address the contact phenomenon with a more inclusive approach of handling the slips and frictional parameters parallelly.The simultaneous initiation of slip in the combined contact mode has been studied and the axial stiffness of the cable is evaluated in lines of Costello(Costello, 1990) for a single layer bi metallic ACSR Dog 
conductor. The phenomenon is attempted throughFiniteElement Analysis procedures and the loss of stiffness at different stages of sliding is evaluated as a function of axial strain. The FEM results are compared with that of Costello(Costello, 1990) and with the experimental results already published. It is hoped that the analysis will be useful to the transmission line utilities as it addresses the realistic conditions on cable behaviour mathematical model.

\section{MATHEMATICAL MODEL}

A mathematical model is developed to predict the strand axial stiffness as a function of applied cable axial strain $\in$ and strand rotation $\gamma$. A single layered strand under the application of an axial force $\mathrm{F}$ and a twisting moment $\mathrm{M}$ is shown in figure $2 \mathrm{a}$ along with its cross-section representation in figure $2 \mathrm{~b}$. The strand cross section consists of central core of radius $R_{c}$ and six helical wires of radius $R_{w}$, the center of which is located at a distance $\mathrm{r}$ from the strand centre known as the helix radius. The centre line of each helical wire is inclined to the strand axis at an angle $\alpha$, known as the helix angle.

The applied cable axial force $\mathrm{F}$ and strand moment $\mathrm{M}$ induce forces and moments in any element of the curved helical wire, the distribution of which is shown in figure 3 . The cable strand axes are indicated by $X_{1}, X_{2}, X_{3}\left(X_{3}\right.$ being along the length of the strand). Any point in the helical wire can be represented by a system of moving axes $\mathrm{x}, \mathrm{y}$ and $\mathrm{z}$ known as normal, binormal and tangential axes with $\mathrm{z}$ being directed along the axial direction of the helical wire. The wire end forces and moments along the normal, bi normal and axial directions are denoted by $N, N^{\prime}, T$ and $G, G^{\prime}, H$ respectively. To maintain equilibrium each wire is acted upon with distributed forces and moments $X, Y, Z$ and $K, K^{\prime}, \theta$ along the respective wire directions.

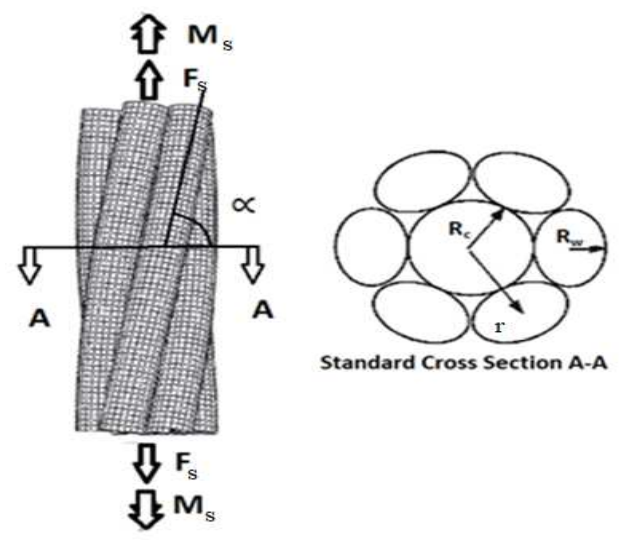

Figure2: a) Strand Geometry, b) Strand Cross Section Area.

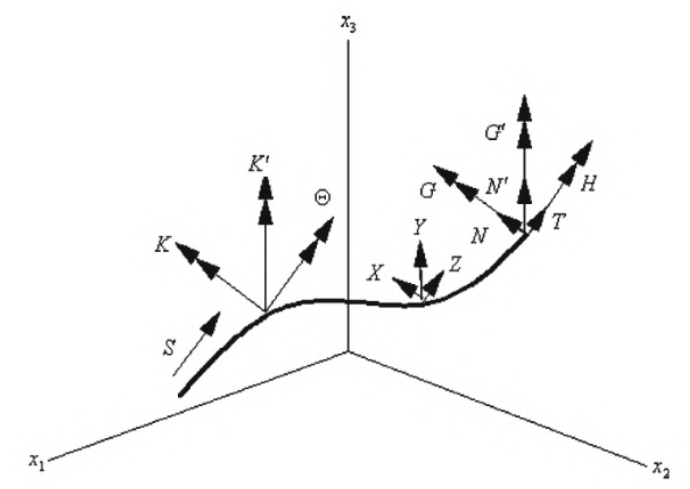

Figure 3:Forces and Moments Acting on Helical Wire. 
Figure 4 shows the developed geometry of a helical wire before and after loading.

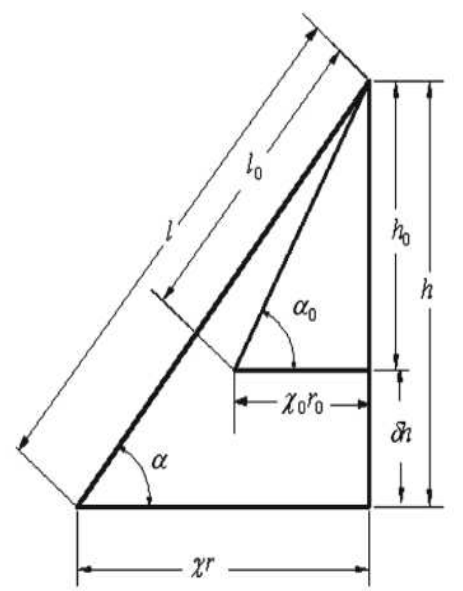

Figure 4: Helical Wire Geometry.

The, following relations can be obtained from the trigonometry (figure 4) as

$$
\begin{gathered}
h=l \sin (\propto) \\
\chi r=l \cos (\propto)
\end{gathered}
$$

As per small deformation theory, theabove equations, the change in strand length $\partial h$ and change in swept angle $\partial \chi$ can be written as

$$
\begin{gathered}
\partial h=l \cos (\propto) \partial \propto+\sin (\propto) \partial l \\
\partial \chi=-(l \sin (\propto) / r) \partial \propto+(\cos (\propto) / r) \partial l
\end{gathered}
$$

From the above relations, change in the helix angle and change in wire length can be written as

$$
\left[\begin{array}{c}
\partial \propto \\
\partial l
\end{array}\right]=\left[\begin{array}{cc}
(\cos (\propto) / l) & -(r \sin (\propto) / l) \\
\sin (\propto) & r \cos (\propto)
\end{array}\right]\left[\begin{array}{l}
\partial h \\
\partial \chi
\end{array}\right]
$$

Letting $\frac{\partial h}{h}=\epsilon \& \frac{\partial X}{X}=\gamma$ as the strand axial strain and strand rotational strain respectively, the following relations can be written for equation 5 .

$$
\partial \propto=\sin \propto \cos \propto(\epsilon-\gamma)
$$

$$
\partial l=l\left(\sin ^{2}(\propto) \times \epsilon+\cos ^{2}(\propto) \times \gamma\right)
$$

The basic kinematic relation of the bi normal curvature and twist of helical wire can be written as

$$
\begin{gathered}
\kappa^{\prime}=\frac{\cos ^{2} \propto}{r} \\
\tau=\frac{\sin (\alpha) \cos (\alpha)}{r}
\end{gathered}
$$


It can be noted that the normal curvature of the helical wire $\kappa$ is zero since the core is straight and helical wire is wound over it. The change in bi normal curvature and twist can be written in terms of the applied strain as follows.

$$
\begin{aligned}
& \Delta \kappa^{\prime}=\frac{\sin (2 \alpha) \cos (\alpha) \sin (\alpha) \times(\gamma-\epsilon)}{r} \\
& \Delta \tau=\frac{1}{r} \cos (2 \alpha) \sin (\alpha) \cos (\alpha) \times(\epsilon-\gamma)
\end{aligned}
$$

The curvature and the twist relations of the helical wire yield the binormal bending moment $G^{\prime}$ and twisting moment $\mathrm{H}$ as follows

$$
\begin{gathered}
G^{\prime}=E_{w} I_{w} \Delta \kappa^{\prime} \\
H=G_{w} J_{w} \Delta \tau
\end{gathered}
$$

Hence, the axial tension in the helical wire $\mathrm{T}$ can be related as

$$
T=\epsilon_{w} E_{w} A_{w}
$$

where, $E_{w}, G_{w}$ are the Young's modulus and the rigidity modulus of the helical wire and $A_{w}, I_{w}, J_{w}$ are respectively the area, area moment of inertia and polar moment of inertia of the helical wire.

The wire axial strain is derived by using Equation 7 as below.

$$
\epsilon_{w}=\frac{\partial l}{l}=\left[\epsilon \sin ^{2}(\alpha)+\gamma \cos ^{2}(\alpha)\right]
$$

The wire bi normal force $N^{\prime}$ can be obtained from the equilibrium equation of the helical wire as in Costello(Costello, 1990).

$$
N^{\prime}=H \kappa^{\prime}-G^{\prime} \tau
$$

The net axial force $F_{s}$ and twisting moment Ms along the strand axis can be obtained from the forces and moments of all the helical wires in a layer and that from the central straight core as under

$$
\begin{gathered}
F_{s}=m\left[T \sin (\alpha)+N^{\prime} \cos (\alpha)\right]+E_{c} A_{c} \epsilon \\
M_{s}=m\left[H \sin (\alpha)+G^{\prime} \cos (\alpha)+T r \cos (\alpha)-N^{\prime} r \sin (\alpha)+G_{c} J_{c}\left(\frac{\partial \chi}{h}\right)\right]
\end{gathered}
$$

where, $\mathrm{m}$ is the number of helical wires in the layer of the strand and $E_{c}, G_{c}$ are the Young's modulus and the rigidity modulus of the rigidity of the core and $A_{c}, J_{c}$ are the area of the cross section and polar moment of inertia of the core wire. The above strand equilibrium equations can be expressed in a matrix form as,

$$
\left[\begin{array}{c}
F_{s} \\
M_{s}
\end{array}\right]=\left[\begin{array}{ll}
F_{\in} & F_{\varnothing} \\
M_{\in} & M_{\varnothing}
\end{array}\right]\left[\begin{array}{c}
\in \\
\frac{\partial \chi}{h}
\end{array}\right]
$$


Where, $F_{\epsilon}, M_{\varnothing}$ are the cable axial stiffness and torsional stiffness coefficients and $F_{\varnothing}$ and $M_{\epsilon}$ are cross coupling coefficients of tension and torsion respectively. When a pure axial load is applied along the strand axis without permitting the rotation of the strand, $\frac{\partial \chi}{h}=0$ and hence the axial stiffness $F_{\epsilon}$ of the strand can be obtained as,

$$
\begin{gathered}
F_{\epsilon}=m\left[E_{w} A_{w} \sin ^{3}(\alpha)+\frac{G J}{r^{2}} \cos (2 \alpha) \sin (\alpha) \cos ^{4}(\alpha)+E I \frac{\sin (2 \alpha) \cos ^{3}(\alpha) \sin ^{2}(\alpha)}{r^{2}}\right] \\
+E_{c} A_{c}
\end{gathered}
$$

Table 1: Properties of Strand used in Example (Gnanavel B K, 2013)

\begin{tabular}{|l|c|}
\hline \multicolumn{1}{|c|}{ Parameters of Strand (Symbol) } & Value \\
\hline Radius of Core $\left(r_{c}\right)$ & $2 \mathrm{~mm}$ \\
\hline Modulus of Elasticity of Core $\left(E_{c}\right)$ & $207000 \mathrm{Mpa}$ \\
\hline Radius of Helical Wire $\left(r_{h}\right)$ & $2 \mathrm{~mm}$ \\
\hline Modulus of Elasticity Helix Wire $\left(E_{h}\right)$ & $69000 \mathrm{Mpa}$ \\
\hline Lay Angle $\left(\alpha^{\circ}\right)$ & $80^{\circ} \mathrm{C}$ \\
\hline Possion's Ratio of Core $\left(\gamma_{c}\right)$ & 0.3 \\
\hline Possion's Ratio of Helix Wire $\left(\gamma_{a l}\right)$ & 0.33 \\
\hline Friction Co-Efficient for Core \& Wire Contact $(\mu)$ & 0.65 \\
\hline Friction Co-Efficient for Wire \& Wire Contact $(\mu)$ & 1.35 \\
\hline
\end{tabular}

\section{FINITE ELEMENT MODEL}

A single layered bimetallic ACSR conductor strand, whose specifications are shown in Table 1, has been considered for the numerical computations and finite element modelling and analysis. The geometrical data of the strand yielded the cable cross section in the combined contact mode. Thestrand core is made by extruding the circular profile along the z-axis for one pitch length,Whereas, the helical wire geometry is made by extruding the circular profile over a helical path with a help of pitch, helix angle and helix radius.

The CAD model of the strand is generated by AUTODESK INVENTOR and is imported into ABAQUS. The material properties such as Young's modulus, Possion's ratio and density are assigned to the model with the help of the software.Brick mesh element also called as hexahedron mesh ( 8 noded) was used for meshing the strand.This type of element supports large strains \& deflections, creep, hyper elasticity, plasticity, stress stiffening and different types of frictional boundary conditions. Three different meshes are used. One is the coarser meshed model for checking the boundary conditions and physics. The other two are fine and finer mesh. Fine mesh has the same mesh density as in Figure 5 a.while another mesh has a greater number of elements near the contact surface as in figure $5 \mathrm{~b}$. Finer mesh mode has 18536 mesh elements out of which 2452 elements were used to mesh the core geometry.FEManalysis has been performed for one pitch length only, due to the periodicity of the geometry, and to reduce the computation time and better efficiency. 

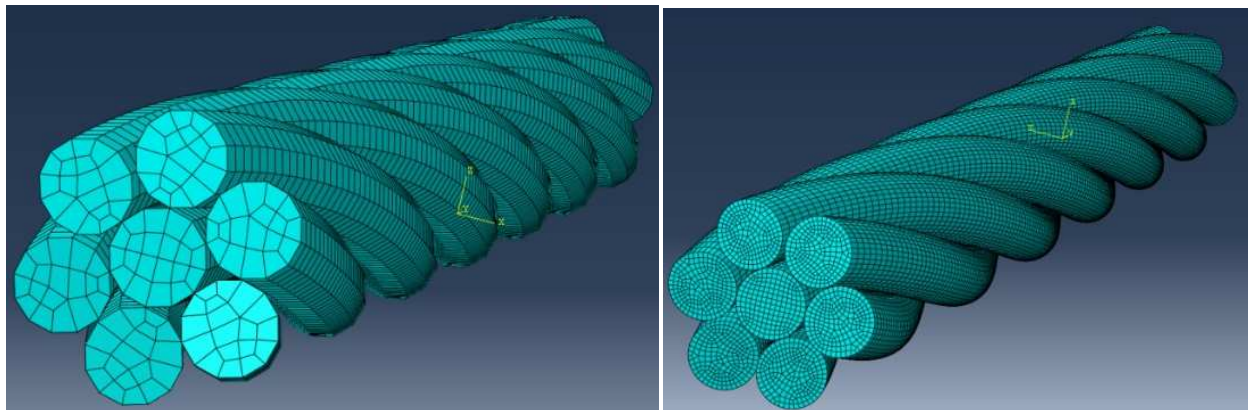

Figure 5: Meshed model of strand a) Fine Mesh b) Finer Mesh.

\section{INTERWIRE FRICTION, BOUNDARY CONDITIONS, AND LOADING}

The movement around the strand longitudinal axis at the free end is permitted but is restrained at the fixed end. In order to avoid unwinding of the wire within the same strand, entire strand end is restrained against rotation. In reality, both theends are fixed with the help of wedges, and this condition was introduced to the FEM model by locking the strand to move only in the axial direction (loading direction).figure 5shows the meshed model with the boundary condition incorporated in it.Surface to surface contact boundary condition is used here for avoiding penetration of master nodes in the slave node. Friction parameters were taken from Table 1. An isotropic Coulomb friction has been adopted in the analysis.

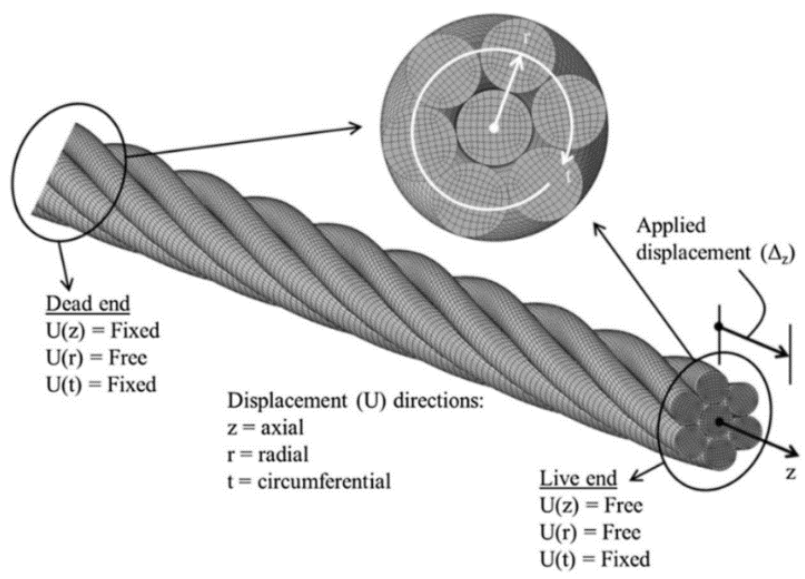

Figure 6:Meshed Model with Boundary Condition.

The strand is analyzed for three cases of frictional behavior.

- A zero-friction assembly, where it is assumed that all the contact interfaces are free to slide over each other. The elongation of the strand is studied under an axial force in a complete state of frictionless behavior.

- The complete interfaces among the wires in the layer are behaving in a frictionless state and the contact interfaces between the core-wire are acted upon with the frictional resistance causing relative sliding at the core wire junction.

- All the cable interfaces i.e. the core-wire and the wire-wire junctions in the layer are influenced by the frictional resistances and the relative sliding that occurs all around.

For all the cases the strand is loaded axially in the $\mathrm{Z}$ direction with the central load ranging from 4000 to $12000 \mathrm{~N}$ with an increment of $2000 \mathrm{~N}$ and the free end elongation is obtained from the finite element model. The results of the axial elongation of the strand are shown in columns 3, 4 and 5 of Table- 2 for all the three cases. 


\section{DISCUSSION OF RESULTS AND MODEL VALIDATION}

The results of the finite element analysis are compared with the numerical results of the theoretical model adopted by Costello and with the published experimental results of Gnanavel(Gnanavel B K, 2013). The axial stiffness of the strand, $F_{\epsilon}$, is evaluated from Equation 20 after accounting the geometrical and material parameters of the strand as in table 1. For an applied cable axial $\operatorname{load}\left(F_{S}\right)$, the axial strain $(\epsilon)$ can be calculated from the Equation 19. The elongation of the strand is obtained from the strain and geometrical length of the strand and is shown in column 2. The experimental results of elongation of the strand as reported in the thesis of Gnanavel(Gnanavel B K, 2013) are shown in column 6 of the table 2.

It can be observed from the Table 2 that, the Costello theoretical model underestimates the elongation. This is due to the fact that cable is assumed as a solid entity where friction in the core wire is infinite making the cable more rigid. The friction less model adopted in the Finite Element analysis has recorded the maximum elongation due to the fact that all the wires are free to move making the strand model as a loose wire assembly. The results of the model where relative sliding at the core and wire interface is permitted register less elongation than the zero-friction complete lose wire assembly. The results of the combined contact model where the frictional effects at all the contact interfaces are permitted, register elongation close to the experimental realities.

\begin{tabular}{|c|c|c|c|c|c|}
\hline \multicolumn{7}{|c|}{ Table 2: Results of Axial Elongation in the Strand } \\
\hline & $\begin{array}{c}\text { Costello } \\
\text { Theoretical } \\
\text { Results } \\
\text { Load(N) }\end{array}$ & \multicolumn{3}{|c|}{ Finite Element Analysis Results } & $\begin{array}{c}\text { Experimen } \\
\text { tal } \\
\text { Results(m } \\
\text { m) } \\
\text { Model(mm) }\end{array}$ \\
\hline 0 & 0 & $\begin{array}{c}\text { Zero Friction } \\
\text { Model(mm) }\end{array}$ & $\begin{array}{c}\text { Core-Wire Friction } \\
\text { model(mm) }\end{array}$ & $\begin{array}{c}\text { Core-Wire \& Wire-Wire } \\
\text { Friction Model(mm) }\end{array}$ & \begin{tabular}{c} 
(miction \\
\hline 2000
\end{tabular} \\
\hline 0.04475 & 0 & 0 & 0.06523 & - \\
\hline 4000 & 0.075115 & 0.140746 & 0.12987 & 0.093963 & 0.09507 \\
\hline 6000 & 0.112743 & 0.187852 & 0.172712 & 0.134078 & 0.13156 \\
\hline 8000 & 0.150372 & 0.232086 & 0.214823 & 0.173649 & 0.17004 \\
\hline 10000 & 0.188 & 0.274499 & 0.256871 & 0.213402 & 0.20425 \\
\hline 12000 & 0.225628 & 0.316072 & 0.298826 & 0.252197 & 0.25471 \\
\hline
\end{tabular}

It can be observed from the table 2 that the Costello's axial elongation results over estimates the experimental values by about $13 \%$. This can be attributed to the infinite friction assumptions at the core wire interfaces. The friction less model underestimates the elongation by about $37 \%$ from that of experimental ones, due to the hypothetical assumption of friction less interfaces. The model that accounts the frictional sliding only at the core wire interfaces underestimates the elongation by about $27 \%$ since, the assembly of the helical wires in the layer are completely frictionless. The FEM model that considers the role of interwire friction at the core-wire and at the wire-wire interfaces leading to the interaction of the friction sliding at all the wire interfaces registers a deviation of about $1.2 \%$ from that of experimental observations. The consideration of frictional sliding at all the interfaces of the cable tallies very closely with the experimental finding, thus validating the finite element simulation adopted in this paper.

Figure 7 shows the plot of variation of the applied axial force and the strand elongation for the Costello and Finite Element models. The experimental values are also plotted against each axial load in figure 7 for reference. 


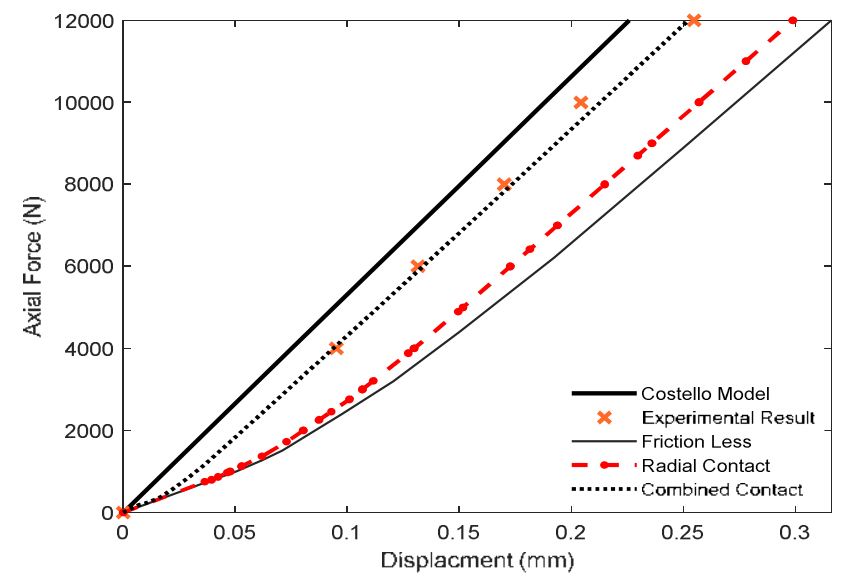

Figure 7: Axial Force vs. Displacement Curve for Strand

\section{CONCLUSIONS}

The modelling of a stranded cable assembly that simultaneously handles the interaction among the core and the helical wire and that between all the helical wires in a layer, has been undertaken to evaluated its axial stiffness. A completely rigid cable where in all the wires are in a monolithic infinite friction behaviour and a total loose wire behaviour, where in all the wire are in a completely frictionless state are set as extreme model and the cable elongation has been studied. Finite element models that consider the interaction of the wires, under a state of frictional contacts at the core wire and wire-wire interfaces are investigated and their axial elongation results are obtained. Eight noded brick element are included for the representation and simulation. A single layered bi metallic ACRS overhead transmission line conductor has been considered for the numerical and finite element analysis. The axial stiffness of the cable assembly has been evaluated as a function of applied as a axial strains and the results are comparted with that of the published experimental results. It has been observed that the finite element modelling that considers the frictional interaction at the core-wire and wire-wire interfaces in the combined contact mode, tallies with the experimental results very closely, thus validating the simultaneous consideration of multi slip modes in the analysis.

\section{REFERENCES}

1. Argatov, I. (2011). Response of a wire rope strand to axial and torsional loads: Asymptotic modeling of the effect of interwire contact deformations. International Journal of Solids and Structures, 48(10), 1413-1423. https://doi.org/10.1016/j.ijsolstr.2011.01.021

2. Chiang, Y. J. (1996). Characterizing simple-stranded wire cables under axial loading. Finite Elements in Analysis and Design, 24(2), 49-66. https://doi.org/10.1016/S0168-874X(97)80001-E

3. Costello, G. A. (1983). Stresses in Multilayered Cables. Journal of Energy Resources Technology, 105(3), 337. https://doi.org/10.1115/1.3230924

4. Costello, G. A. (1990). Theory of Wire Rope, Springer. Springer Science \& Business Media.

5. Elata, D., Eshkenazy, R., \& Weiss, M. P. (2004). The mechanical behavior of a wire rope with an independent wire rope core. International Journal of Solids and Structures, 41(5-6), 1157-1172. https://doi.org/10.1016/j.ijsolstr.2003.11.021

6. Foti, F., \& de Luca di Roseto, A. (2016). Analytical and finite element modelling of the elastic-plastic behaviour of metallic strands under axial-torsional loads. International Journal of Mechanical Sciences, 115-116, 202-214. https://doi.org/10.1016/j.ijmecsci.2016.06.016 
7. Gnanavel B K. (2013). Contact models in cable assemblies. Retrieved from http://hdl.handle.net/10603/11427

8. Jiang, W. G., Yao, M. S., \& Walton, J. M. (1999). A concise finite element model for simple straight wire rope strand. International Journal of Mechanical Sciences, 41(2), 143-161. https://doi.org/10.1016/S0020-7403(98)00039-3

9. Jiang, Wen Guang, Warby, M. K., \& Henshall, J. L. (2008). Statically indeterminate contacts in axially loaded wire strand. European Journal of Mechanics, A/Solids, 27(1), 69-78. https://doi.org/10.1016/j.euromechsol.2007.02.003

10. Kastratović, G., Vidanović, N., Bakić, V., \& Rašuo, B. (2014). On finite element analysis of sling wire rope subjected to axial loading. Ocean Engineering, 88, 480-487. https://doi.org/10.1016/j.oceaneng.2014.07.014

11. Spak, K., Agnes, G., \& Inman, D. (2013). Cable Modeling and Internal Damping Developments. Applied Mechanics Reviews, 65(1), 010801. https://doi.org/10.1115/1.4023489

12. Stanova, E., Fedorko, G., Fabian, M., \& Kmet, S. (2011). Computer modelling of wire strands and ropes Part I: Theory and computer implementation. Advances in Engineering Software, 42(6), 305-315. https://doi.org/10.1016/j.advengsoft.2011.02.008

13. Usabiaga, H., Ezkurra, M., Madoz, M. A., \& Pagalday, J. M. (2008). Experimental test for measuring the normal and tangential line contact pressure between wire rope and sheaves. Experimental Techniques, 32(5), 34-43. https://doi.org/10.1111/j.1747-1567.2007.00294.x

14. Utting, W. S., \& Jones, $N$. (1987a). The response of wire rope strands to axial tensile loads-Part I. Experimental results and theoretical predictions. International Journal of Mechanical Sciences, 29(9), 605-619. https://doi.org/10.1016/00207403(87)90033-6

15. Utting, W. S., \& Jones, N. (1987b). The Response of Wire Rope Strands to Axial Tensile Loads-Part II Comparison of Experimental Results and Theoretical Predictions. International Journal of Mechanical Sciences, 29(9), 621-636. https://doi.org/10.1016/0020-7403(87)90033-6

\section{AUTHOR'S PROFILE}

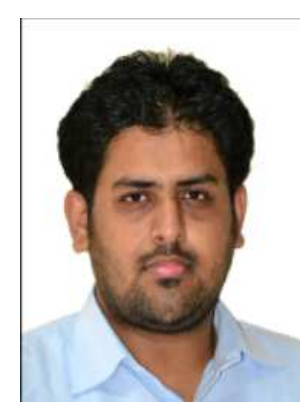

HADIYA PRITESH DULABHAI, Assistant Professor of Mechanical Engineering has completed his BE (Mechanical Engineering) from VTU, Belgaum, and MS from Blekinge Institute of Technology, Sweden. He has 5 years of experience in Academics. He has been an enthusiastic participant at various International and National Conferences/Seminars/Workshops around the World and also presented his research work for the same. His area of research is mechanical vibration and stress-strain. 


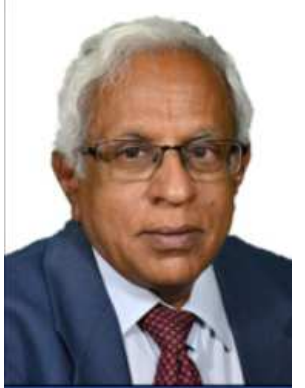

Dr. N.S. Parthasarathy has obtained his Bachelor degree in MechanicalEngineering and Master's degree inEngineering Design and obtaineda $\mathrm{PhD}$ in the area of Vibrations in1999.He has 24 years of teachingexperience in College ofEngineering, Guindy, AnnaUniversity, Chennai and has an exclusive 12 years Researchand Development experience at Central Power ResearchInstitute, Bangalore and at UHV Research Lab Hyderabad.His specific expertise is in the areas of Contact Mechanics,FEM, Vibration of transmission lines and in the design ofdampers. He has 6 years of teaching experience as a Professorin Mechanical Engineering, MVJ College of Engineering,AMC College ofEngineering,Bangalore and is currently working in CHRIST (Deemed to be University) Bangalore.

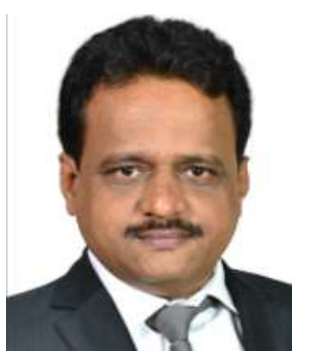

Dr. GURUMOORTY S HEBBAR, BE, M.Tech, Ph.D. His area of the research area isdiesel and alternative fuel engineswith a focus on combustion and pollution control aspects. Presently, he is involved in research on Biofuels from Algae andWastes cooked oil. Process optimization of pond grown algae into biodiesel and measuring its performance\&pollution characteristics using a research engine is an ongoing project funded by the University. Few other biodiesels are also being experimented with different blending options by him. Ethanol from bamboo stems is another ongoing project. Bamboo powdering and reactor designs are customized by our own research team. He is also involved in a project on Energy Management of a Hybrid Vehicle. 
